\title{
Adenomyoma of the small intestine a rare pathological lead point for intussusception in an infant
}

\author{
You-Jung Bak, Udo Rolle, Stefan Gfroerer and Henning C Fiegel ${ }^{*}$
}

\begin{abstract}
Introduction: Intussusception is a typical abdominal emergency in early childhood.

Case description: We report a case of an infant in the typically affected age group with an intussusception triggered by a rare benign intramural intestinal adenomyoma as a pathological lead point. The infant had the typical symptoms of a recurrent idiopathic ileocolic intussusception.
\end{abstract}

Discussion and evaluation: Idiopathic intussusception is frequent in the infant age group. Contrary to that, reports on pathological lead points for intussusceptions are sparse in the toddler age.

Conclusions: That case illustrates that even in intussusceptions in the typically affected age group, it is important to be aware of pathological lead points, especially if the intussusceptions are recurrent.

Keywords: Intussusception; Intestinal adenomyoma; Pathological lead point

\section{Background}

Intussusception occurs when a proximal part of the bowel invaginates into a more distal part, typically within the ileocoecal region, which occurs commonly in infants and children between 3 months and 4 years of age. Typical symptoms in these patients include a triad of acute abdominal pain, vomiting and bloody stools; however, regularly, patients present with variable, nonspecific symptoms. Ultrasonography is the established standard for diagnosis of intussusception and has a high sensitivity and specificity (Lehnert et al. 2009). Idiopathic intussusception occurs due to swollen mesenteric lymph nodes in patients in the typically affected age group that have been affected by viral infection or non-specific immunologic factors. If recurrent intussusception or intussusception occur in older children, the presence of a pathological lead point must be considered. Herein, we report and discuss the case of an infant in the typically affected age group with an ileocolic intussusception triggered by an adenomyoma of the distal ileum wall, a

\footnotetext{
* Correspondence: henning.fiegel@kgu.de

Department of Pediatric Surgery and Pediatric Urology, Johann Wolfgang Goethe University of Frankfurt, Theodor-Stern-Kai 7, D-60590 Frankfurt am Main, Germany
}

\section{Case description}

A previously healthy 11-month-old girl was admitted to our department with a 2-day history of colicky abdominal pain, intermittent agitation and sudden screaming. There were no episodes of bilious vomiting, bloody stools or fever. An ileocolic intussusception was diagnosed externally by ultrasonography, and immediate ultrasonographyguided hydrostatic reduction was attempted. Because complete reduction could not be achieved, the infant was transferred to our hospital. Physical examination showed a lethargic, dehydrated infant with a distended but nontender abdomen and decreased bowel sounds. Ultrasonography confirmed the ileocolic intussusception. Colonic enema reduction was performed immediately with successfully reposition, proved by ultrasound. The infant was rehydrated overnight, showed no symptoms the following morning and tolerated drinking well. Twelve hours after reduction, the infant presented again with crampy abdominal pain and vomiting. Ultrasonography showed again the typical findings of ileocolic intussusception (Figures 1 and 2). Repeated hydrostatic reduction was not successful. Therefore, 


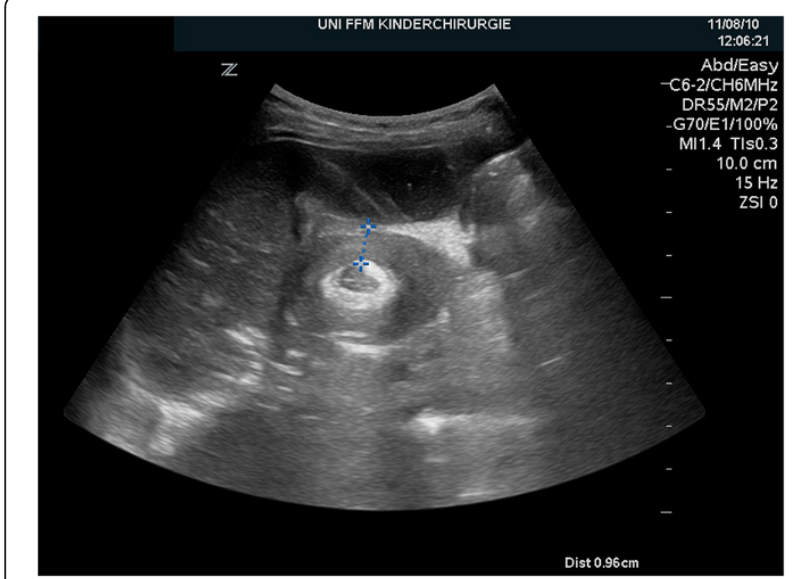

Figure 1 Ultrasonography of the right upper abdominal quadrant revealed the typical ultrasonographic "target sign" of ileocolic intussusception after recurrent symptoms in the reported patient.

emergency surgery was indicated. During laparotomy, an ileoileocolic intussusception was identified and reduced (Figure 3). After reduction, a palpable intraluminal mass presented as possible lead point of the intussusception approximately $10 \mathrm{~cm}$ from the ileocecal valve (Figure 4). Segmental resection of the ileum and reanastomosis were performed. The further recovery period was uneventful, and the infant was discharged 6 days after the operation.

Pathological findings were as follows. The mass was a $1 \times 1 \times 1 \mathrm{~cm}$ polypoid lesion covered with hemorrhagic and partly necrotic mucosa. Microscopically, the tumor was located in the submucosa and composed of glandular structures lined by mucin-secreting columnar epithelium and smooth muscle bundles (Figure 5). These findings were compatible with the diagnosis of adenomyoma of the ileum. Elsewhere, the ileum showed

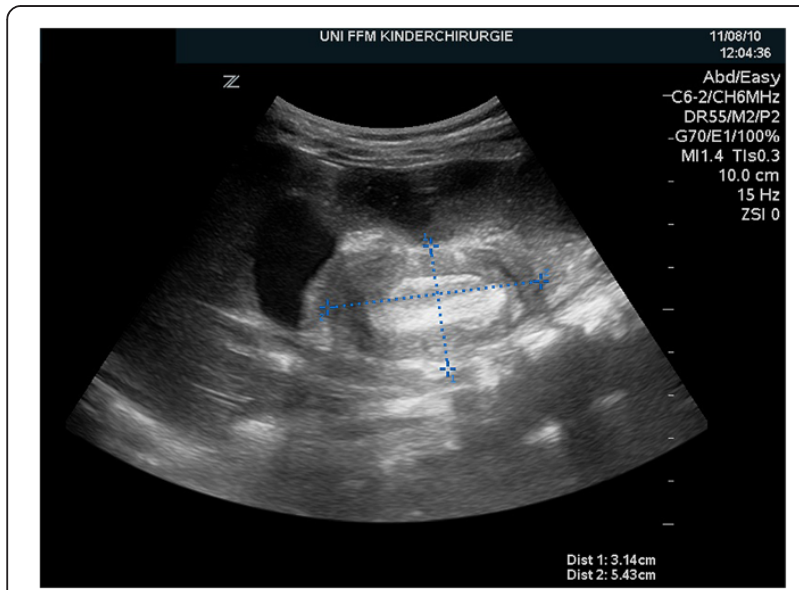

Figure 2 Ultrasonography of the right upper abdominal quadrant revealed the typical ultrasonographic finding of "pseudo-kidney".

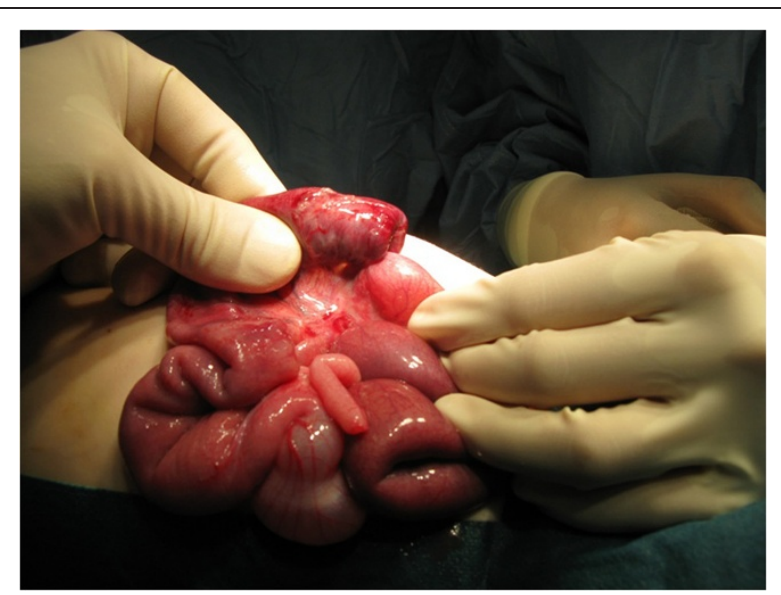

Figure 3 Intraoperative findings of the ileocolic intussusception before manual reduction.

severe mucosal ulceration and necrosis in addition to subtotal perforating enteritis with hemorrhagic infarction, all of which were consistent with changes resulting from the intussusception.

\section{Discussion and evaluation}

Intussusception is a common cause of bowel obstruction in infants and toddlers, with the greatest incidence in infants aged 3-9 months (Lehnert et al. 2009, Gfrorer et al. 2009). There is a seasonal incidence, with peaks in spring and autumn resembling the most typical periods of seasonal gastroenteritis and respiratory tract infections. Most infants do not have a specific lead point. Hypertrophied Peyer's patches and reactive lymph node hyperplasia, which result from prior viral infection, can serve as a lead point for idiopathic intussusception. Specific lead points (e.g., Meckel diverticulum, intestinal polyps, lymphomas, and intestinal duplication) are more

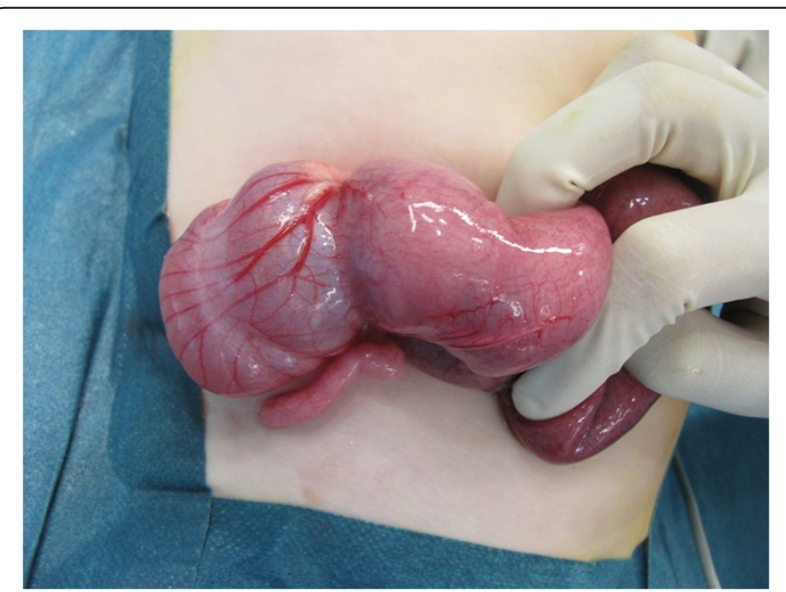

Figure 4 Intraoperative findings of the palpable mass in the distal ileum after reduction of the intussusception. 


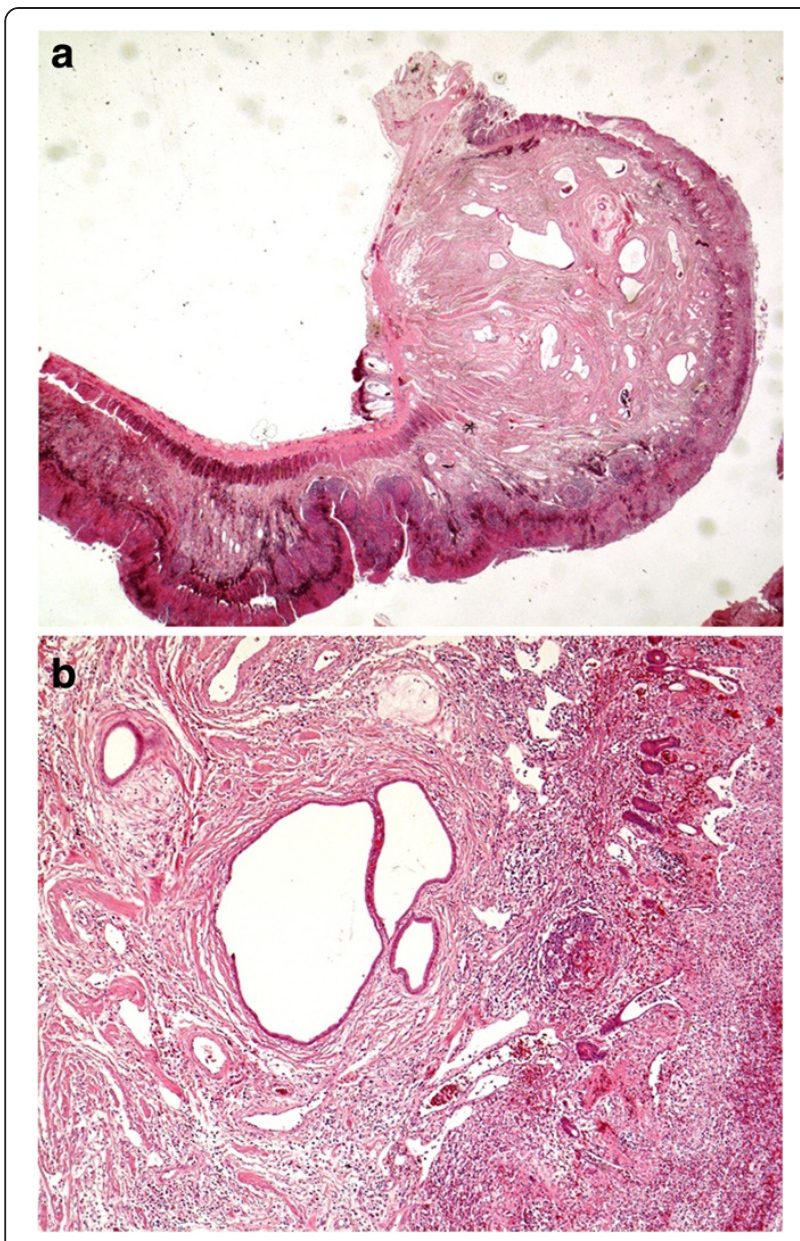

Figure 5 Histological image: Adenomyoma localised in the submucosa of the ileum. In addition a necrotising enteritis is shown. Primary magnification 0.5 (a) and $4 \times$ (b). commonly found in older children and adults. Ultrasonography is the preferred diagnostic tool in intussusception and has a sensitivity of $98-100 \%$ and a specificity of 88-100\% (Lehnert et al. 2009, Gfrorer et al. 2009). Hydrostatic reduction under ultrasound control and contrast enema are established therapies for the treatment of intussusception, with a success rate of $70-90 \%$ (Lehnert et al. 2009, Gfrorer et al. 2009). Immediate surgery is indicated in patients who have peritonitis, sepsis, evidence of perforation, unsuccessful non-operative repositioning or a clear finding of pathological lead points. In cases occurring in individuals not in the typical age group or in cases of recurrent intussusceptions, a pathological lead point must be excluded.

Adenomyoma of the gastrointestinal tract is a rare benign lesion localized at the stomach, small intestine and biliary ducts (Zhu et al. 2010). Adenomyoma of the stomach is usually asymptomatic. Its occurrence in the small intestine of children is extremely rare. However, in the small intestine, intussusception is its most common complication, which has been reported in 13 cases so far (Table 1). The reported cases had significantly varied ages, with a range from 2 days to 82 years. In our case, the infant was of the typical age and had the symptoms most commonly associated with idiopathic ileocolic intussusception, but the intussusception was nonetheless due to a pathological finding.

\section{Conclusions}

Adenomyoma of the small bowel is a rare cause of intussusception in all age groups. The here presented case shows, that even in patients where intussusceptions occur in the typically affected age group, it is important to be aware of pathological lead points, especially in recurrent intussusceptions.

Table 1 Previous reported cases of adenomyoma in intussusception

\begin{tabular}{|c|c|c|c|c|c|}
\hline No. & First author & Year & Age & Surgical diagnosis & Histopathology \\
\hline 1 & Schwartz et al. & 1958 & 8 months & intussusception & myoepithelial hamartoms \\
\hline 2 & Gal et al. & 1986 & 82 years & intussusception & adenomatous hamartoma \\
\hline 3 & Kim et al. & 1990 & 7 years & intussusception & adenomyoma \\
\hline 4 & Gal et al. & 1991 & 9 months & intussusception & adenomyoma \\
\hline 5 & Lamki et al. & 1993 & 1 year & intussusception & adenomyoma \\
\hline 6 & Serour et al. & 1994 & 3 years & intussusception & adenomyoma \\
\hline 7 & Chan et al. & 1994 & 5 months & intussusception & adenomyoma \\
\hline 8 & Gonzalvez et al. & 1995 & 2 years & intussusception & adenomyoma \\
\hline 9 & Yamagami et al. & 1997 & 4 months & intussusception & adenomyoma \\
\hline 10 & Lee et al. & 2001 & 18 years & intussusception & adenomyoma \\
\hline 11 & Park et al. & 2003 & 7 months & intussusception & adenomyoma \\
\hline 12 & Mouravas et al. & 2003 & 18 months & intussusception & adenomyoma \\
\hline \multirow[t]{2}{*}{13} & Takeda et al. & 2011 & 68 years & intussusception & adenomyoma \\
\hline & here described case & 2013 & 11 months & intussusception & adenomyoma \\
\hline
\end{tabular}




\section{Consent}

Written informed consent was obtained from the parents for the publication of this report and any accompanying images.

\section{Competing interests}

The authors declare that they have no competing interests.

\section{Authors' contributions}

YJB collected the data and drafted the manuscript. HCF performed the literature study and assisted in drafting the manuscript. SG and UR were involved in the case and in the critical revision of the drafted manuscript All authors read and approved the final manuscript.

\section{Acknowledgments}

We wish to acknowledge ML Hansmann (Institute of Pathology, Goethe-University Frankfurt/M.) for providing the histological images.

Received: 24 July 2014 Accepted: 8 October 2014

Published: 18 October 2014

\section{References}

Chan YF, Roche D (1994) Adenomyoma of the small intestine in children. J Pediatr Surg 29(12):1611-1612

Gal R, Kolkow Z, Nobel M (1986) Adenomyomatosis hamartoma of the small intestine: a rare cause of intussusception in an adult. Am J Gastroenterol 12:1209-1211

Gal R, Rath-Wolfson GM, Kessler E (1991) Adenomyoma of the small intestine. Histopathology 18:369-371

Grorer S, Fiegel H, Rolle U (2009) Invagination. Monatsschr Kinderheilkd 157:917-924

Gonzalvez J, Marco A, Andujar M, Iniguez L (1995) Myoepithelial hamartoma of the ileum: a rare cause of intestinal intussusception in children. Eur J Ped Surg 5:303-304

Kim CJ, Choe GY, Chi JG (1990) Foregut choristoma of the ileum (adenomyoma) - a case report. Ped Pathol 10:799-805

Lamki N, Woo CL, Watson AB Jr, Kim HS (1993) Adenomyomatosis hamartoma causing ileoileal intussusception in a young child. Clin Imaging 17:183-185

Lee JS, Kim HS, Jung JJ, Kim YB (2001) Adenomyoma of the small intestina in an adult: a rare cause of intussusception. J Gastroenterol 37(7):556-559

Lehnert T, Sorge I, Till H, Rolle U (2009) Intussusception in children - clinical presentation, diagnosis and management. Int J Colorectal Dis 24:1187-1192

Mouravas V, Koutsoumis G, Patoulias J, Kostopoulos I, Kottakidou R, Kallergis K, Kepertis C, Liolios N (2003) Adenomyoma of the small intestine in children: a rare cause of intussusception: a case report. Turk J Pediatr 45(4):345-347

Park HS, Lee SO, Lee JM, Kang MJ, Lee DG, Chung MJ (2003) Adenomyoma of small intestine: report of two cases and review of the literature. Pathol Int 53:111-114

Schwartz SI, Radwin HM (1958) Myoepithelial hamartoma of the ileum causing intussusception. AMA Arch Surg 77:102-104

Serour F, Gorenstein A, Lipnitzky V, Zaidel L (1994) Adenomyoma of the small bowel: a rare cause of intussusception in childhood. J Pediatr Gastroenterol Nutr 18(2):247-249

Takeda M, Shoji T, Yamazaki M, Higashi Y, Maruo H (2011) Adenomyoma of the jleum leading to intussusception. Case Rep Gastroenterol 5(3):602-609

Yamagami T, Tokiwa K, Iwai N (1997) Myoepithelial harmartoma of the ileum causing intussusception in an infant. Pediatr Surg Int 12:206-207

Zhu HN, Yu JP, Luo J, Jiang YH, Li JQ, Sun WY (2010) Gastric adenomyoma presenting as melena; a case report and literature review. World I Gastroenterol 16(15):1934-1936

doi:10.1186/2193-1801-3-616

Cite this article as: Bak et al:: Adenomyoma of the small intestine a rare pathological lead point for intussusception in an infant. SpringerPlus 2014 3:616.

\section{Submit your manuscript to a SpringerOpen ${ }^{\circ}$ journal and benefit from:}

- Convenient online submission

- Rigorous peer review

- Immediate publication on acceptance

- Open access: articles freely available online

- High visibility within the field

- Retaining the copyright to your article

Submit your next manuscript at $\gg$ springeropen.com 